\title{
DYNAMIC CARDIAC COMPRESSION IMPROVES CONTRACTILE EFFICIENCY OF THE HEART
}

Osamu Kawaguchi, MD

Yoichi Goto, $\mathrm{MD}^{\mathrm{b}}$

Yuichi Ohgoshi, MD

Hitoshi Yaku, MD

Mitsuya Murase, $\mathrm{MD}^{\mathrm{a}}$

Hiroyuki Suga, $\mathrm{MD}^{\mathrm{c}}$
The effect of dynamic cardiac compression on left ventricular contractile efficiency was assessed in terms of the pressure-volume relationship and myocardial oxygen consumption. In 11 excised cross-circulated dog hearts, the ventricle was directly compressed during systole (dynamic cardiac compression). Measurements for pressure-volume area (a measure of total mechanical energy), external work, and myocardial oxygen consumption were done before and during dynamic cardiac compression. Dynamic cardiac compression increased pressure-volume area by $28 \% \pm 17 \%$ (mean plus or minus the standard deviation) and external work by $24 \% \pm 20 \%$ $(p=0.0000185$ and 0.0000212 , respectively) at given end-diastolic and stroke volumes without affecting myocardial oxygen consumption. As a result, the oxygen cost of pressure-volume area, that is, the slope of the myocardial oxygen consumption-pressure-volume area relationship, significantly decreased by $16 \% \pm 13 \%(p=0.0000135)$ whereas the pressurevolume area-independent myocardial oxygen consumption was unchanged. Then, contractile efficiency, that is, the reciprocal of the slope of the myocardial oxygen consumption-pressure-volume area relationship in joules significantly improved from $45 \% \pm 8 \%$ to $53 \% \pm 13 \%(p=$ 0.0000437). When the native myocardial oxygen consumption-pressurevolume area relationship was assessed by subtracting the dynamic cardiac compression pressure applied to the heart, the slope of the myocardial oxygen consumption-pressure-volume area relationship returned to the control level. This indicates that the contractile efficiency of the native heart was not affected by dynamic cardiac compression. We conclude that dynamic cardiac compression enhances left ventricular pump function by improving the contractile efficiency of the overall heart leaving the energetics of the native heart unchanged. (J Thorac Cardiovasc Surg 1997;113:923-31)
D ynamic cardiac compression (DCC), which enhances ventricular pump function by direct mechanical compression of the heart, has been pro-

From the Department of Thoracic Surgery, Nagoya University School of Medicine, Nagoya ${ }^{a}$; the Department of Cardiovascular Dynamics, National Cardiovascular Center Research Institute, Osaka; and the Department of Physiology II, Okayama University Medical School, Okayama, ${ }^{c}$ Japan.

Supported in part by a grant-in-aid for scientific research (07508003) from the Ministry of Education, Science, Sports, and Culture.

Received for publication Sept. 10, 1996; revisions requested Oct. 17, 1996; revisions received Nov. 5, 1996; accepted for publication Nov. 19, 1996.

Address for reprints: Osamu Kawaguchi, MD, c/o Professor Mitsuya Murase, Department of Thoracic Surgery, Nagoya University School of Medicine, 65 Tsurumai, Showaku, Nagoya 466 Japan.

Copyright (C 1997 by Mosby--Year Book, Inc.

$0022-5223 / 97 \$ 5.00+0 \quad \mathbf{1 2} / \mathbf{1} / \mathbf{7 9 3 3 2}$ posed and tried for assisting hearts with long-term failure as a result of myocardial damage. ${ }^{1-4}$ Clinically, latissimus dorsi muscle wraps have been used as a therapeutic tool for patients with severe left ventricular (LV) dysfunction, ${ }^{4,5}$ and direct mechanical ventricular actuation has been applied as a bridge to heart transplantation. ${ }^{6}$ Cardiomyoplasty has been done in more than 400 patients with chronic heart failure and has resulted in significant improvements in symptoms in more than $75 \%$ of subjects. ${ }^{7}$ However, when the effectiveness of DCC is assessed in terms of systolic hemodynamic performance, the results with respect to enhancement of arterial pressure, ejection fraction, and cardiac output are not consistent. Also, it remains unknown to what extent improvements in symptoms and ejection fraction result from a direct systolic compression effect and what from myocardial oxygen sparing.

It is widely accepted that DCC in cardiomyoplasty 
A

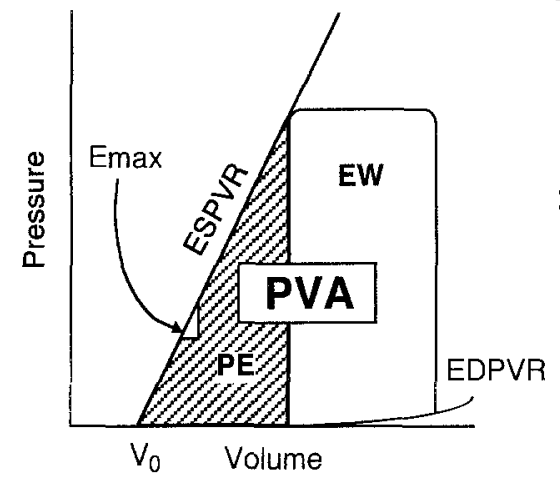

B

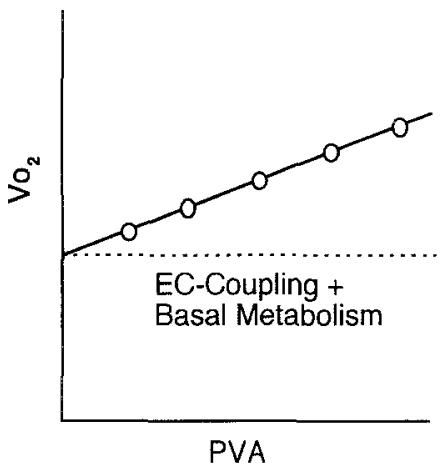

C

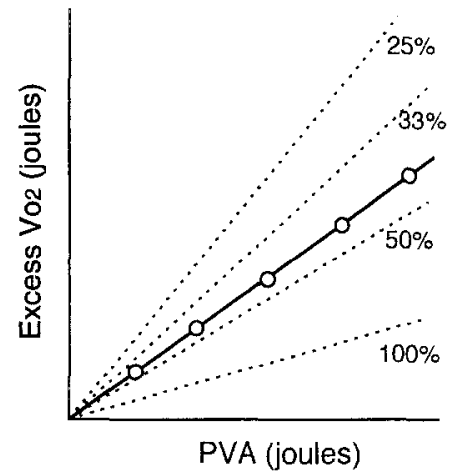

Fig. 1. A, Schematic illustration of ventricular P-V loop, systolic PVA, external mechanical work $(E W)$, and end-systolic potential energy (PE). ESPVR, End-systolic P-V relation; EDPVR, end-diastolic P-V relation. $\mathbf{B}$, The relation between $\mathrm{Vo}_{2}$ and total mechanical energy (PVA). $\mathrm{Vo}_{2}$ above the $\mathrm{Vo}_{2}$-axis intercept represents excess $\mathrm{VO}_{2}$ used for mechanical contraction, whereas $\mathrm{Vo}_{2}$ below the $\mathrm{Vo}_{2}$-axis intercept represents nonmechanical energy expenditure for excitation-contraction $(E C)$ coupling and basal metabolism. The slope of the $\mathrm{Vo}_{2}$-PVA relationship indicates the oxygen cost of PVA and its reciprocal is called contractile efficiency. $\mathrm{C}$, The relation between excess $\mathrm{Vo}_{2}$ and PVA and a family of isoefficiency lines. The excess $\mathrm{Vo}_{2}$ is equal to the total $\mathrm{Vo}_{2}$ minus unloaded $\mathrm{Vo}_{2}$ or $\mathrm{Vo}_{2}$-axis intercept. The isoefficiency is a constant efficiency from the excess $\mathrm{VO}_{2}$ to PVA.

or direct mechanical ventricular actuation is likely to alter ventricular loading conditions, and hence difficulties in characterizing the effects of DCC on cardiac pump function with the use of conventional, load-dependent hemodynamic parameters have been suggested. ${ }^{8,9}$ Because the slope of the endsystolic pressure-volume $(\mathrm{P}-\mathrm{V})$ relation, $\mathrm{E}_{\max }$, sensitively reflects acute changes in contractile state in a manner independent of ventricular loading conditions, ${ }^{10-12}$ many studies have used $\mathrm{E}_{\max }$ to characterize the contractility change in cardiomyoplasty. ${ }^{9}, 13,14$ However, the notion that the beneficial effects of cardiomyoplasty are a result of systolic enhancement is still controversial. ${ }^{14-16}$

The P-V diagram provides not only the information on contractility' but also that on mechanical energy in terms of the $\mathrm{P}-\mathrm{V}$ area (PVA) generated by contraction within a cardiac cycle (Fig. 1, $A$ ). PVA has been shown to correlate linearly with myocardial oxygen consumption $\left(\mathrm{VO}_{2}\right)$ at any given contractile state (Fig. $1, B$ ). ${ }^{11,12,17,18}$ Therefore $\mathrm{E}_{\max }$ and PVA have advantages in the study of the effectiveness of DCC from the standpoint of both ventricular mechanics and energetics. Using the framework of the $\mathrm{P}-\mathrm{V}$ diagram, we previously reported that DCC increased both $E_{\max }$ and external work without increasing $\mathrm{Vo}_{2} \cdot{ }^{19}$ However, it remains unclear whether and how DCC affects ventricular contractile efficiency assessed from the relation between
$\mathrm{VO}_{2}$ and PVA. The purpose of this study was to characterize the effectiveness of DCC in terms of the contractile efficiency of the LV.

\section{Material and methods}

Heart preparation. A total of 11 isolated, cross-circulated canine hearts were studied. All animals involved in this study received humane care in compliance with the "Guiding Principles in the Care and Use of Animals" approved by the Council of the American Physiological Society (revised 1980) and the "Guide for the Care and Use of Laboratory Animals" published by the National Institutes of Health (NIH Publication No. 85-23, revised 1985).

In each experiment, two mongrel dogs were anesthetized with ketamine hydrochloride $(7 \mathrm{mg} / \mathrm{kg}$ by intramuscular injection) followed by sodium pentobarbital $(25$ $\mathrm{mg} / \mathrm{kg}$ by intravenous injection). The details of the surgical procedure of the heart preparation have been described previously. ${ }^{17},{ }^{19}$ Briefly, the dogs were heparinized $(10,000$ IU per dog by intravenous injection) and the heart-lung section was isolated in one dog (heart donor). The left subclavian artery and the right ventricle were connected to the common carotid artery and the external jugular vein, respectively, of the other dog (supporter) via cross-circulation tubings. The cross-circulated beating heart was excised from the chest after ligation of the pulmonary hili and removal of the lung. Coronary circulation was never stopped during the preparation.

The left atrium was widely opened, and all chordae tendineae were cut. A thin latex rubber balloon (unstressed volume of $60 \mathrm{ml}$ ) tied on a balloon-to-pump connector was fitted in the LV and secured at the mitral 
anulus. A miniature pressure gauge (Konigsberg P-7, Konigsberg Instruments Inc., Pasadena, Calif.) was placed inside the apical end of the balloon through the ventricular apex. The balloon was connected to a volume servo pump system that precisely controlled and accurately measured instantaneous LV volume (Fig. 2). ${ }^{17}$

Coronary blood flow (except for the small amount of LV thebesian flow) was continuously measured with an electromagnetic flowmeter (MFV-2100, Nihon Koden, Tokyo, Japan) placed in the middle of the venous drainage tube from the right ventricle. The thebesian blood flow was a negligible fraction (1\% to $2 \%$ ) of the total coronary blood flow. The difference in oxygen content between arterial and coronary venous blood $\left(\mathrm{AVO}_{2}\right)$ was continuously measured by bypassing parts of both the arterial and venous blood flows from the cross-circulation tubes through an oximeter (PWA-200S, Erma Optical Works Ltdl., Tokyo, Japan). The oximeter was calibrated against an IL-282 CO-oximeter (Instrumentation Laboratory, Lexington, Mass.) at the beginning of each experiment. The right ventricle was kept collapsed by continuous hydrostatic drainage of the coronary venous blood to minimize the contribution of the right ventricular $\mathrm{Vo}_{2}$ to the measured total $\mathrm{Vo}_{2}$.

The temperature of the heart was maintained at $35^{\circ}$ to $37^{\circ} \mathrm{C}$ with a heater around the arterial cross-circulation tube and under the box containing the heart. A pair of pacing electrodes was screwed into the left atrial appendage. A ventricular epicardial electrogram was monitored with another pair of electrodes to determine the onset of contraction and to trigger the volume servo pump.

The arterial pressure of the support dog served as the coronary perfusion pressure of the heart preparation. The mean level of this pressure was relatively constant throughout each experiment $(112 \pm 23 \mathrm{~mm} \mathrm{Hg})$. To prevent hypotension of the support dog after the initiation of cross circulation, indomethacin solution $(0.3 \mathrm{mg} / \mathrm{kg}$ by intravenous injection) was administered. ${ }^{19,20}$ Although indomethacin had a substantial effect on the stability of the blood pressure of the support dog, its direct effects on cardiac contractility and $\mathrm{Vo}_{2}$ were negligible. Fresh blood collected from the heart donor or $10 \%$ dextran 40 solution was infused intravenously to the support dog as needed to maintain the arterial pressure of the support dog. The lungs of the support dog were ventilated with room air mixed with oxygen to maintain the arterial pH, oxygen tension, and carbon dioxide tension within their physiologic ranges. At the end of each experiment, the LV (with the interventricular septum) and the right ventricle (free wall only) were weighed. The weights were $72.5 \pm 11.0 \mathrm{gm}$ and $21.5 \pm 5.4 \mathrm{gm}$, respectively.

DCC. The ventricular portion of the isolated heart was placed in an airtight chamber lined with a thin latex rubber sac to fit the ventricle (Fig. 2) ${ }^{19,20}$ An air cylinder (Super Purnp, SP 3892, VIVITRO System Inc., Victoria, British Columbia, Canada) was actuated in synchrony with the LV epicardial electrogram. The stroke volume of the cylinder was set to a constant value to induce $20 \%$ to $30 \%$ increases in end-systolic pressure at a midrange LV volume at the beginning of each experiment. Compression pressure provided by an actuator (dynamic compression pressure, DCP) was continuously monitored with a Gold-

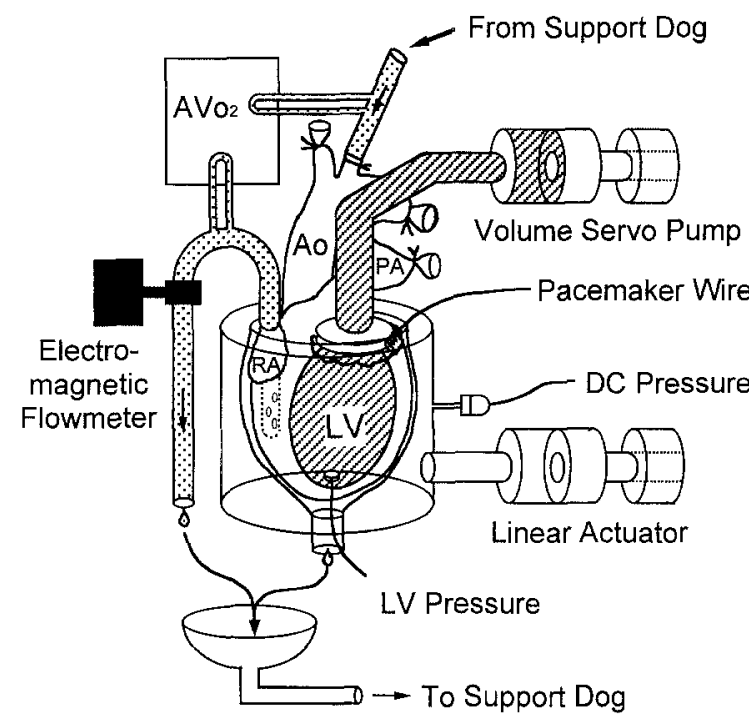

Fig. 2. Schematic diagram of the excised, cross-circulated heart preparation. $\mathrm{Ao}$, Aorta; $\mathrm{AVO}_{2}$, arteriovenous oxygen content difference analyzer; $D C$ pressure, dynamic compression pressure; $P A$, pulmonary artery; $R A$, right atrium.

Statham P-50 pressure transducer (Viggio-Spectramed Inc., Critical Care Division, Oxnard, Calif.). The heart was firmly connected to the volume servo pump and preserved from any displacement from the chamber during DCC.

Experimental protocol. Each heart was paced at a constant rate slightly higher than the natural sinus rhythm observed at the beginning of each experiment. Measurements were started after all tracings of ventricular pressure, coronary blood flow, and $\mathrm{AVO}_{2}$ were stabilized.

At five to six different settings of end-diastolic volume (11.8 to $30.9 \mathrm{ml} ; 21.8 \pm 5.0 \mathrm{ml}$ ), ejecting contraction was produced at a constant stroke volume $(4.0$ to $5.5 \mathrm{ml})$. $\mathrm{E}_{\text {max }}$ PVA, external work, and $\mathrm{Vo}_{2}$ were measured during steady-state contractions as a control run. DCC was started and measurements were repeated as a DCC-on run at each setting of end-diastolic volume. After the cessation of DCC, measurement was repeated during a DCC-off run (second control).

Data analysis. All data were sampled at 2 msec intervals for 2 seconds, analyzed on-line with a signal processor (7T18, NEC San-ei, Tokyo, Japan), and stored on a floppy disk. Measurements were repeated twice at an interval of 0.5 to 1 minute under the same steady-state condition to confirm reproducibility of the data. The means of the two measurements were used for analysis.

$L V$ mechanics. The contractile state of the beating LV was assessed by ventricular end-systolic elastance $(E[t])$ as follows:

$$
\mathrm{E}(\mathrm{t})=\frac{\mathrm{P}(\mathrm{t})}{\mathrm{V}(\mathrm{t})-\mathrm{V}_{0}}
$$

where $P(t)$ and $V(t)$ are $L V$ instantaneous pressure and volume, respectively. ${ }^{10} \mathrm{~V}_{0}$ is the $\mathrm{LV}$ volume at which peak isovolumic pressure was zero. $\mathrm{E}_{\max }$ was the maximum 


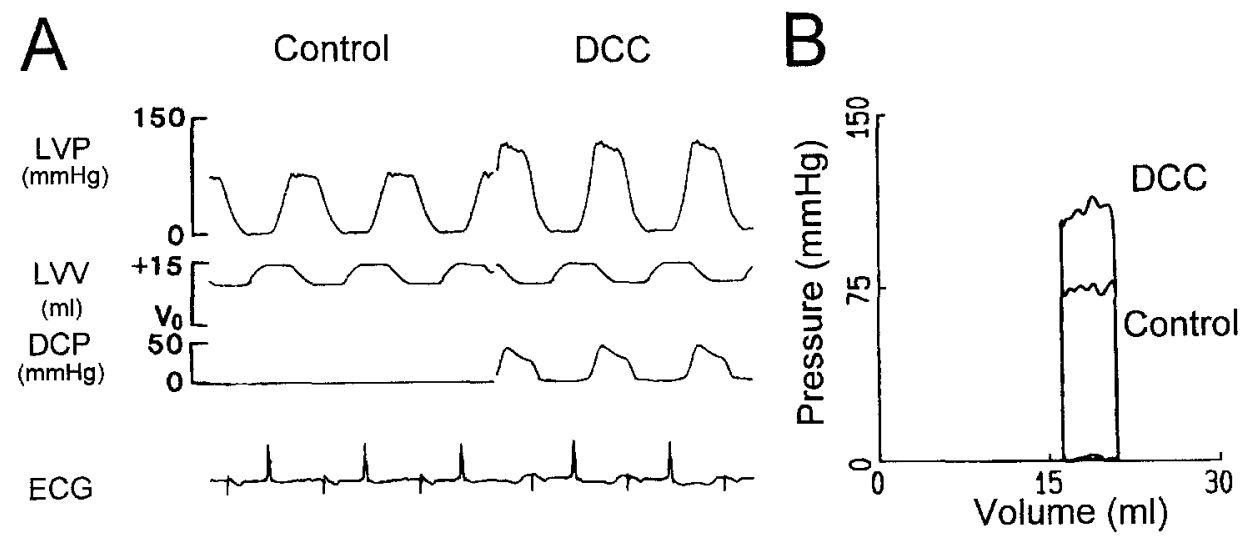

Fig. 3. Representative tracing of $\mathrm{P}-\mathrm{V}$ loops in the control and DCC runs. $L V P, \mathrm{LV}$ pressure; $L V V, \mathrm{LV}$ volume; $D C P$, dynamic compression pressure; $E C G$, electrocardiogram.

value of $\mathrm{E}(\mathrm{t})$. Fig. $1, A$, shows a schematic P-V diagram. $\mathrm{E}_{\text {max }}$ is the slope of the straight end-systolic P-V relationship line connecting $\mathrm{V}_{0}$ and the left upper corner of each $P-V$ trajectory. $E_{\max }$ was normalized for $100 \mathrm{gm} \mathrm{LV.} \mathrm{PVA}$ is the area bounded by the end-systolic and end-diastolic $\mathrm{P}-\mathrm{V}$ relationships and the systolic segment of the P-V trajectory. ${ }^{11,18}$ It consists of external work within the P-V loop and mechanical potential energy on the origin side of the loop. Potential energy is generated during contraction and reasonably assumed to be dissipated as heat during relaxation. ${ }^{21}$ PVA represents the total mechanical energy generated by a ventricular contraction on the basis of the time-varying elastance model of the ventricle. ${ }^{18,21}$

The pressure generated by the native heart during DCC was assessed by subtracting instantaneous DCP from the corresponding LV pressure when we wanted to exclude the effect of DCC. Then, from this pressure of the native heart, $E_{\max }, P V A$, and external work of the native heart were calculated for a DCP-subtracted run.

$\mathrm{Vo}_{2}$. The $\mathrm{Vo}_{2}$ of the heart was determined as the product of mean coronary blood flow per minute and $\mathrm{AVo}_{2}$; this value was divided by steady-state heart rate to obtain the $\mathrm{Vo}_{2}$ per beat. $\mathrm{Vo}_{2}$ was normalized for $100 \mathrm{gm}$ $\mathrm{LV}$ after the unloaded right ventricular free wall $\mathrm{Vo}_{2}$ was subtracted from the measured total $\mathrm{Vo}_{2}$ in each heart. The unloaded right ventricular (RV) $\mathrm{Vo}_{2}$ was calculated as follows:

$$
\mathrm{RVVO}_{2}=\frac{\text { Total unloaded } \mathrm{Vo}_{2} \times \mathrm{RV} \text { free wall weight }}{\text { Total ventricular weight }}
$$

The total unloaded $\mathrm{VO}_{2}$ was measured at $\mathrm{V}_{0}$ with zero PVA.

$\mathrm{VO}_{2}-\mathrm{PVA}$ relation. The relation between $\mathrm{LV} \mathrm{Vo}_{2}$ and PVA was obtained in each run. Linear regression analysis was used to determine the slope $\left(\mathrm{ml} \mathrm{O}_{2} \cdot \mathrm{mm} \mathrm{Hg}^{-1} \cdot \mathrm{ml}\right)$ and $\mathrm{Vo}_{2}$ intercept $\left(\mathrm{ml} \mathrm{O}_{2} \cdot\right.$ beat $\left.{ }^{-1} \cdot 100 \mathrm{gm} \mathrm{LV}^{-1}\right)$ of each $\mathrm{VO}_{2}$-PVA relationship. Because PVA is a measure of total mechanical energy (Fig. 1, B), the slope (oxygen cost of PVA) of the $\mathrm{Vo}_{2}$-PVA relationship, or the ratio of excess $\mathrm{VO}_{2}$ above the unloaded $\mathrm{Vo}_{2}$ to $\mathrm{PVA}$, has been considered the ratio of energy input that is used exclusively for mechanical contraction to total mechanical energy output. ${ }^{12}$ Because both PVA and $\mathrm{VO}_{2}$ can be converted into joules, the inverse of the oxygen cost of PVA (both in joules per beat per $100 \mathrm{gm} \mathrm{LV}$ ) represents the contractile efficiency that reflects the chemomechanical energy transduction rate of crossbridge cycling as in Fig. 1, $C{ }^{12}$

Statistics. Two-way analysis of variance was applied to compare individual variables among the control, DCC-on, and DCP-subtracted runs. When analysis of variance showed statistical significance by $\mathrm{F}$ test, mean values were compared by the least significant difference method. Analysis of covariance was also applied to compare the slope and intercept of the $\mathrm{Vo}_{2}$-PVA relationship between the control and DCC-on runs. Probability values smaller than 0.05 were considered statistically significant. Data are presented as mean plus or minus the standard deviation unless otherwise indicated.

\section{Results}

Fig. $3, A$, shows representative tracings of the control and DCC measurements. End-diastolic and stroke volumes were kept constant at $21.0 \mathrm{ml}$ and 4.8 $\mathrm{ml}$, respectively. DCP increased during systole in synchrony with the LV contraction. In this example, DCC increased end-systolic pressure from $73 \mathrm{~mm}$ $\mathrm{Hg}$ to $104 \mathrm{~mm} \mathrm{Hg}$, whereas it did not change end-diastolic pressure or coronary blood flow. Fig. 3, $B$, shows the P-V loops of the control and DCC contractions. DCC increased $\mathrm{E}_{\max }$ from 5.1 to 7.2 $\mathrm{mm} \mathrm{Hg} \cdot \mathrm{ml} \cdot 100 \mathrm{gm} \mathrm{LV}^{-1}$. As a result, PVA and external work increased from 1086 and $607 \mathrm{~mm}$ $\mathrm{Hg} \cdot \mathrm{ml} \cdot 100 \mathrm{gm} \mathrm{LV}^{-1}$ in the control contraction to 1553 and $855 \mathrm{~mm} \mathrm{Hg} \cdot \mathrm{ml} \cdot 100 \mathrm{gm} \mathrm{LV}^{-1}$ in the DCC contraction, respectively.

Fig. 4 compares the $\mathrm{Vo}_{2}$-PVA relationship among the control, DCC, and DCP-subtracted conditions. During DCC, the slope of the $\mathrm{VO}_{2}$-PVA relationship 

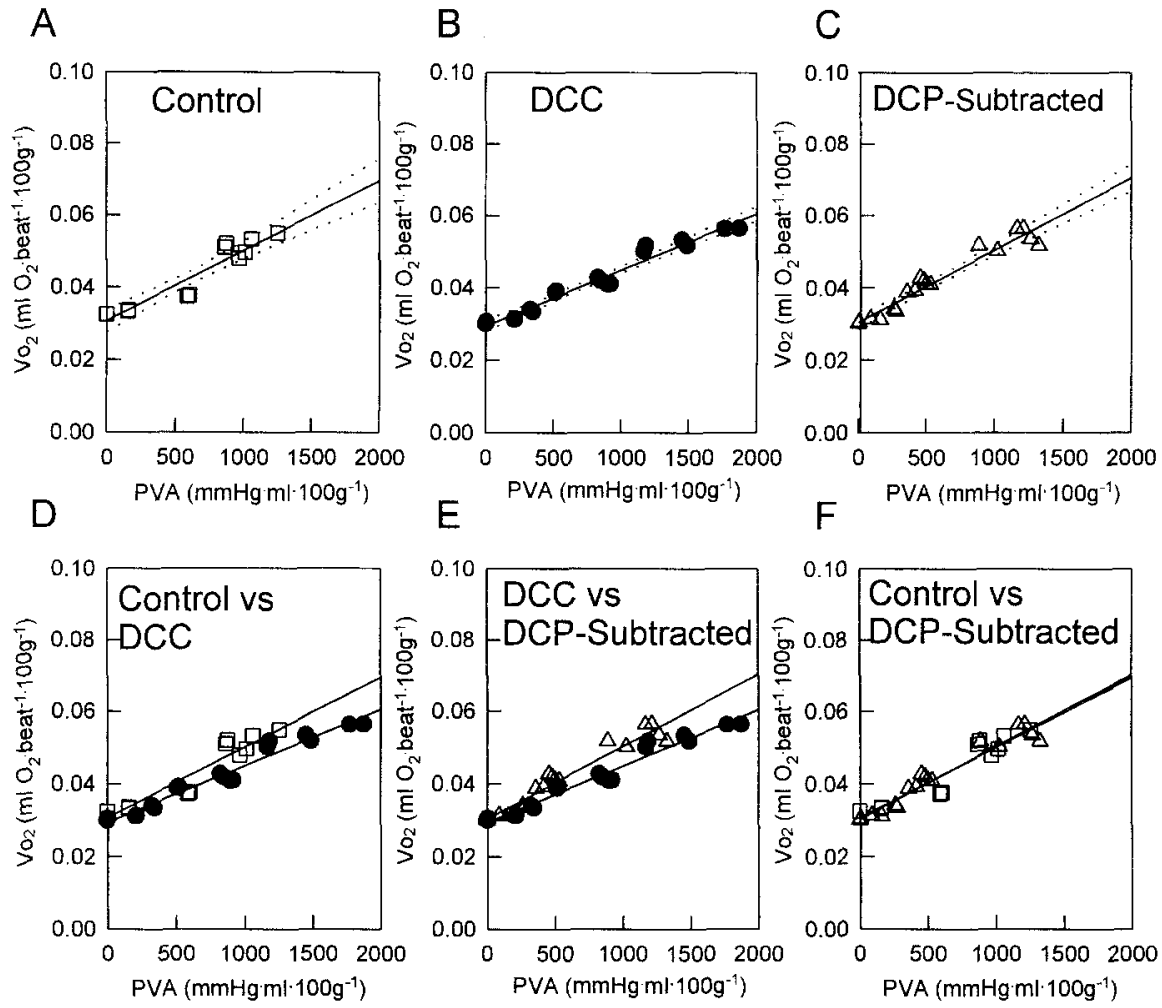

Fig. 4. Representative $\mathrm{Vo}_{2}$-PVA relationship in the control, DCC, and DCP-subtracted conditions. A, Control $\mathrm{VO}_{2}-\mathrm{PVA}$ relationship. $\mathbf{B}$, DCC $\mathrm{VO}_{2}$-PVA relationship. $\mathrm{C}$, DCP-subtracted $\mathrm{VO}_{2}$-PVA relationship. D, Control $\mathrm{Vo}_{2}$-PVA relationship versus DCC $\mathrm{Vo}_{2}$-PVA relationship. E, DCC $\mathrm{Vo}_{2}$-PVA relationship versus DCP-subtracted $\mathrm{Vo}_{2}$-PVA relationship. F, Control $\mathrm{Vo}_{2}$-PVA relationship versus DCP-subtracted $\mathrm{Vo}_{2}$-PVA relationship.

decreased by $20 \%$ (from $1.95 \times 10^{-5} \mathrm{ml} \mathrm{O} \cdot 2 \cdot \mathrm{mm}$ $\mathrm{Hg}^{-1} \cdot \mathrm{ml}$ to $1.56 \times 10^{-5} \mathrm{ml} \mathrm{O}_{2} \cdot \mathrm{mm} \mathrm{Hg}^{-1} \cdot \mathrm{ml}, p<$ 0.05 , by analysis of covariance) whereas the intercept was unchanged (from $0.0308 \mathrm{ml} \mathrm{O}_{2}$. beat $^{-1} \cdot 100 \mathrm{gm} \mathrm{LV}^{-1}$ to $0.0294 \mathrm{ml} \mathrm{O}_{2} \cdot$ beat $^{-1} \cdot 100 \mathrm{gm}$ $\left.\mathrm{LV}^{-1}\right)$. The calculated contractile efficiency increased from $34 \%$ to $43 \%$. When DCP was subtracted to calculate PVA generated by the native heart, the DCP-subtracted $\mathrm{VO}_{2}$-PVA relationship was superimposable on the control $\mathrm{Vo}_{2}$-PVA relationship. There was no significant difference in the slope or the intercept between two $\mathrm{VO}_{2}$-PVA relationships by analysis of covariance. Thus this indicates that the corrected contractile efficiency returned to the control level.

Table I summarizes the parameters at the maximal LV volume. DCC with a DCP of $19.6 \pm 8.1 \mathrm{~mm}$ $\mathrm{Hg}$ increased end-systolic pressure by $28 \% \pm 21 \%$ $(p=0.00000116), \mathrm{E}_{\max }$ by $21 \% \pm 19 \%(p=$ $0.0000101)$, PVA by $28 \% \pm 17 \%(p=0.0000185)$, and external work by $24 \% \pm 20 \%(p=0.0000212)$.
Although DCC decreased $\mathrm{V}_{0}$ by $8 \% \pm 8 \%$, practically this decrease was small. Despite these significant increases in the cardiodynamic parameters, neither coronary blood flow nor $\mathrm{Vo}_{2}$ changed. When $\mathrm{E}_{\max }$, PVA, and external work were recalculated by subtracting DCP from corresponding LV pressure (DCP-subtracted), the values did not differ from those of the control run. This implies that DCC did not affect the native heart contractility nor pumping performance at given end-diastolic and stroke volumes. This is also confirmed by unchanged $\mathrm{VO}_{2}$ values between the control and DCC-on runs.

Table II compares the $\mathrm{Vo}_{2}$-PVA relationship and the contractile efficiency in all 11 hearts. The oxygen cost of PVA significantly decreased by $16 \% \pm 13 \%$ $(p=0.0000135)$ whereas the PVA-independent $\mathrm{VO}_{2}$ remained unchanged. As a result, the contractile efficiency significantly improved from $45 \% \pm 8 \%$ to $53 \% \pm 13 \%(p=0.0000437)$. When the native $\mathrm{Vo}_{2}$-PVA relationship was assessed by subtracting DCP, the oxygen cost of PVA returned to the 
Table I. LV mechanics and energetics at the maximal ventricular volume before and during DCC

\begin{tabular}{|c|c|c|c|c|}
\hline & Control & $D C C$-on & $D C C$-off & DCP subtracted \\
\hline $\mathrm{EDP}(\mathrm{mm} \mathrm{Hg})$ & $10.2 \pm 4.9$ & $7.9 \pm 4.1$ & $9.2 \pm 4.3$ & NA \\
\hline $\mathrm{EDV}(\mathrm{m} l)$ & $26.8 \pm 2.9$ & $26.9 \pm 2.8$ & $26.8 \pm 2.7$ & NA \\
\hline ESP $(\mathrm{mm} \mathrm{Hg})$ & $103 \pm 28$ & $131 \pm 37^{*}$ & $100 \pm 33$ & NA \\
\hline $\mathrm{ESV}(\mathrm{ml})$ & $22.3 \pm 3.0$ & $22.3 \pm 2.9$ & $22.2 \pm 2.7$ & NA \\
\hline $\mathrm{DCP}(\mathrm{mm} \mathrm{Hg})$ & $-1.4 \pm 2.1$ & $19.6 \pm 8.1^{*}$ & $-3.8 \pm 4.5$ & NA \\
\hline $\mathrm{E}_{\max }\left(\mathrm{mm} \mathrm{Hg} \cdot \mathrm{ml}^{-1} \cdot 100 \mathrm{gm} \mathrm{LV}\right)$ & $5.5 \pm 2.7$ & $6.5 \pm 3.5^{*}$ & $4.9 \pm 2.7$ & $4.7 \pm 3.0$ \\
\hline $\mathrm{V}_{0}(\mathrm{ml})$ & $7.0 \pm 0.1$ & $6.5 \pm 0.7 \dagger$ & $7.0 \pm .02$ & NA \\
\hline PVA $\left(\mathrm{mm} \mathrm{Hg} \cdot \mathrm{ml} \cdot 100 \mathrm{gm} \mathrm{LV}^{-1}\right)$ & $1775 \pm 570$ & $2190 \pm 653^{*}$ & $1671 \pm 636$ & $1755 \pm 711$ \\
\hline $\left.\mathrm{EW}(\mathrm{mm}) \mathrm{Hg} \cdot \mathrm{ml} \cdot 100 \mathrm{gm} \mathrm{LV}^{-1}\right)$ & $691 \pm 245$ & $826 \pm 281^{*}$ & $638 \pm 274$ & $607 \pm 232$ \\
\hline Coronary blood flow $(\mathrm{ml})$ & $66.0 \pm 19.8$ & $70.2 \pm 25.8$ & $70.8 \pm 27.5$ & NA \\
\hline $\mathrm{BVo}_{2}\left(\mathrm{ml} \mathrm{O}_{2} \cdot\right.$ beat $\left.^{-1} \cdot 100 \mathrm{gm} \mathrm{LV}^{-1}\right)$ & $0.0514 \pm 0.0099$ & $0.0523 \pm 0.0122$ & $0.0503 \pm 0.0119$ & NA \\
\hline
\end{tabular}

Values are mean plus or minus the standard deviation of the mean. $B \mathrm{O}_{2}, \mathrm{Vo}_{2}$ of the $\mathrm{LV}$ per beat; $E D P$, end-diastolic pressure; $E D V$, end-diastolic volume; $E S P$, end-systolic pressure; $E S V$, end-systolic volume; $E W$, external work; $N A$, not applicable.

${ }^{*} p<0.01$ by two-way analysis of variance.

$t p<0.05$ by two-way analysis of variance.

Table II. Effect of DCC on the oxygen cost of PVA and contractile efficiency

\begin{tabular}{lcccc}
\hline & Control & DCC-on & DCC-off & DCP subtracted \\
\hline Oxygen cost of PVA & $1.59 \pm 0.22$ & $1.30 \pm 0.24^{*}$ & $1.53 \pm 0.23$ & $1.55 \pm 0.28$ \\
$\quad\left(\times 10^{-5} \mathrm{ml} \mathrm{O}_{2} \mathrm{ml}^{-1} \cdot \mathrm{mm} \mathrm{Hg}\right)$ & & & & \\
PVA-independent Vo $_{2}$ & $0.0252 \pm 0.0030$ & $0.0241 \pm 0.0055$ & $0.0258 \pm 0.0050$ & $0.0256 \pm 0.0051$ \\
$\quad\left(\mathrm{ml} \mathrm{O} \mathrm{O}_{2} \cdot\right.$ beat $\left.^{-1} \cdot 100 \mathrm{gm} \mathrm{LV}^{-1}\right)$ & & & & \\
Correlation coefficient & $0.997-0.962(0.980)$ & $0.996-0.919(0.974)$ & $0.997-0.901(0.980)$ & $0.995-0.834(0.963)$ \\
Contractile efficiency $(\%)$ & $44.8 \pm 7.5$ & $53.4 \pm 12.7^{*}$ & $44.6 \pm 6.8$ & $44.3 \pm 8.6$ \\
\hline
\end{tabular}

Mean plus or minus the standard deviation are indicated. Correlation coefficient lists the range and median.

${ }^{*} p<0.01$ by two-way analysis of variance.

control level. This implies that the contractile efficiency of the native heart was not affected by DCC. DCC significantly increased PVA so as to improve the overall contractile efficiency while keeping the mechanoenergetics of the native heart per se unaffected.

\section{Discussion}

In the present study, we have demonstrated an improvement in contractile efficiency during DCC by measuring the relationship between $\mathrm{Vo}_{2}$ and cardiac mechanical energy in terms of PVA. DCC did not affect PVA-independent $\mathrm{VO}_{2}$, which is considered to be related primarily to $\mathrm{Ca}^{++}$handling for excitation-contraction coupling and basal metabolism to maintain myocardial viability and integrity of the native heart. ${ }^{13}$ This is in contrast to the effects of most positive inotropic interventions including catecholamines, $\mathrm{Ca}^{++}$, and various new cardiotonic agents that elevate the $\mathrm{Vo}_{2}$-PVA relationship in a parallel manner with increases in $\mathrm{E}_{\max }{ }^{11,12}$ The assessment of the oxygen cost of PVA during DCC allowed us to characterize the oxygen-saving effect of DCC regardless of LV loading conditions. The decreased slope of the $\mathrm{Vo}_{2}$-PVA relationship indicates a load-dependent oxygen-saving effect of DCC, that is, the oxygen-saving effect of DCC becomes greater at higher LV loading conditions. These changes seem favorable for the failing heart, because the same PVA can be generated by a smaller $\mathrm{Vo}_{2}$ particularly when the $\mathrm{LV}$ is enlarged and oxygen supply and adenosine triphosphate production are limited. Under DCC, the reduced oxygen demand for a given PVA is expected to improve cardiac reserve.

Effect of DCC on the end-systolic P-V relationship. Mechanical heart support has two principal functions: (1) to maintain adequate peripheral circulation and (2) to partially unload a damaged ventricle so as to augment cardiac reserve. In DCC, the former requires the enhancement of LV pump function to increase cardiac output and the latter requires the unloading effect of the $\mathrm{LV}$ to reduce $\mathrm{Vo}_{2}$. Previous efforts to elucidate the effects of cardiomyoplasty have focused mostly on the former function., 13, 16, 22, 23 The P.V relationship has been used to characterize the effect of cardiomyoplasty such as the enhancement of LV pump function by 
comparing $E_{\max }$ between DCC-on and DCC-off conditions. ${ }^{8,13,23}$ However, the effect of DCC on the $\mathrm{LV}$ end-systolic $\mathrm{P}-\mathrm{V}$ relationship has been controversial (Fig. 5, $A$ and $C$ ). That is, the enhancement of $\mathrm{E}_{\max }$ has been inconsistent although DCC in cardiomyoplasty induced a significant leftward shift of the end-systolic P-V relationship., 14-16, 23, 24 Increases in $\mathrm{E}_{\max }$ have been recognized to represent enhancement of LV contractility. On the other hand, the physiologic significance of leftward shift of the end-systolic P-V relationship in cardiomyoplasty is still unclear.

The mechanism whereby DCC induces the leftward shift of the end-systolic P-V relationship in the in situ heart is unclear. However, the significant shift of $\mathrm{V}_{0}$ rather than enhancement of $\mathrm{E}_{\max }$ in cardiomyoplasty can partly be explained by a lack of uniform compression provided by the cardiomyoplasty muscle. In cardiomyoplasty, first, the LV is partly covered by the right ventricle and, second, it is reasonable to assume that the power transmitted to the LV from the latissimus dorsi muscle is unlikely to be uniform (depending on the muscle damage caused by the surgical technique, inadequate muscle size, the wrapping technique, and other variables). On the other hand, in our experiment, the right ventricle was totally vented and the pressure provided from DCC could be uniformly transmitted to the LV. Although we detected a leftward shift of $V_{0}$ during DCC, practically it was small. Global pharmacologic interventions have been known to induce changes in the slope of the end-systolic P-V relationship without affecting $\mathrm{V}_{0}{ }^{25}$ On the other hand, the regional damage to the heart induced by coronary occlusion results in a rightward shift of the end-systolic P-V relationship, which induces the $V_{0}$ shift instead of $E_{\max }$ change. ${ }^{26}$ Therefore assessment of the slope of the end-systolic P-V relationship alone may not be appropriate to elucidate the mechanical effect of cardiomyoplasty in the in situ condition.

Effect of DCC on the oxygen cost of PVA. It is helpful to simulate the effect of DCC on the $\mathrm{VO}_{2}$ PVA relationship when we estimate the physiologic significance of changes in the end-systolic P.V relationship. Our data suggested that during DCC, the native $\mathrm{P}-\mathrm{V}$ loop moves from loop I to loop III along the native end-systolic $\mathrm{P}-\mathrm{V}$ relationship in Fig. 5, $\mathcal{A}$, because DCC does not affect the $\mathrm{E}_{\max }$ of the native heart when the overall $\mathrm{E}_{\max }$ is enhanced by DCC. Because of the decrease in PVA and hence the $\mathrm{Vo}_{2}$ of the native heart, the $\mathrm{Vo}_{2}$-PVA data point should
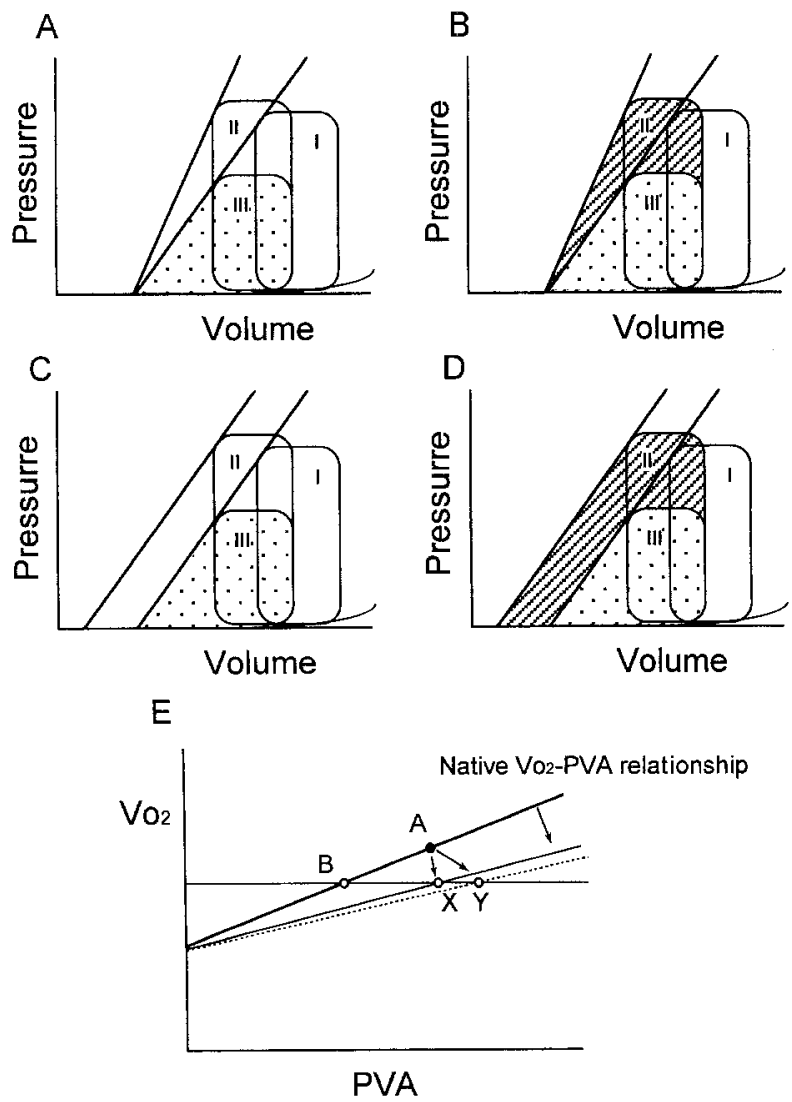

Fig. 5. Schematic diagram of $\mathrm{P}-\mathrm{V}$ relationship and $\mathrm{VO}_{2}-$ PVA relationship during DCC. A and B, P-V loop with increased $\mathrm{E}_{\max }$. $\mathrm{P}-\mathrm{V}$ loop shifts to the left with increases in $\mathrm{E}_{\max }$ during DCC. Loops I and II represent the P-V loops of the control and DCC conditions, respectively. The dotted areas represent the PVA of the native heart. $\mathbf{C}$ and D, P-V loop with a leftward, parallel shift of the endsystolic P-V relationship. Loop I represents the P-V loop of the control. Loop III represents the P-V loop of the native heart during DCC. The areas including both the dashed and dotted areas in panels $\mathbf{B}$ and $\mathbf{D}$ represent the PVA of overall heart during DCC. E, Schematic diagram of $\mathrm{VO}_{2}-\mathrm{PVA}$ relationship during DCC. With decreases in PVA of the native heart in DCC, $\mathrm{Vo}_{2}$ decreased to move the $\mathrm{Vo}_{2}$-PVA data point from $A$ to $B$ along the native $\mathrm{Vo}_{2}$-PVA relationship. $X$ and $Y$ indicate the expected $\mathrm{Vo}_{2}$-overall PVA data plot under enhanced or leftward shift of the end-systolic P-V relationship, respectively.

move from $\mathrm{A}$ to $\mathrm{B}$ along the native $\mathrm{Vo}_{2}$-PVA relationship as shown in Fig. 5, E. However, when this $\mathrm{Vo}_{2}$ is plotted against overall PVA, the $\mathrm{Vo}_{2^{-}}$ PVA data point should be located to $X$ where the overall contractile efficiency is improved by reducing 
the oxygen cost of PVA. When the end-systolic P-V relationship shifts leftward in a parallel manner by DCC as in Fig. 5, $C$, the overall PVA should be enhanced to a greater extent as shown by loop II in Fig. 5, D. Under this condition, the greater increase in the overall PVA shifts the $\mathrm{Vo}_{2}$-PVA points to $\mathrm{Y}$ in Fig. 5, E, resulting in further reduction in the oxygen cost of PVA. Therefore, in DCC, the leftward shift of the end-systolic P-V relationship, even without a change in $\mathrm{E}_{\max }$, may be as important as $\mathrm{E}_{\max }$ increase.

Effects of DCC on the native heart. The coincidence of $E_{\max }$, the oxygen cost of PVA, and PVAindependent $\mathrm{Vo}_{2}$ between the control and the DCPsubtracted conditions indicates that the inotropic and energetic states of the native heart are unchanged during DCC (Table II). As a result, the mechanical energy of the native heart in terms of PVA can be estimated by subtracting the mechanical energy applied to the heart as shown in the dashed area of loop II in Fig. 5, $B$ and $C$. However, it has never been assessed how efficiently mechanical energy can be applied from the assisting muscles to the heart. The effects of DCC in cardiomyoplasty and direct mechanical ventricular actuation have been estimated by eliminating native heart performance (for example by fibrillating the heart). ${ }^{27}$ However, the real effects of DCC on the beating heart are not necessarily the same as those on the fibrillating heart. To characterize the real unloading effect and systolic enhancement of cardiomyoplasty, measurements for both $\mathrm{Vo}_{2}$ and mechanical energy transmitted to the heart are essential.

DCC in this study was provided by a pneumatic system and the profile of the power generation with this system is likely to be different from that of the latissimus dorsi muscle in cardiomyoplasty. Therefore the skeletal muscle wrap may not function in the same way. Further studies are necessary to elucidate the effects of DCC in cardiomyoplasty for the in situ beating heart.

In conclusion, DCC increases $E_{\max }$ and PVA without increasing $\mathrm{VO}_{2}$ in a manner such that the overall contractile efficiency increases. However, DCC does not change the native $\mathrm{Vo}_{2}$-PVA relationship because DCC does not affect the mechanical and energetic performance of the heart itself. DCC enhances LV pump function because the mechanical work added to the native heart by DCC appears as such in the overall performance of the compressed heart.

\section{REFERENCES}

1. Chen W, Justicz AG, Soberman MS, Alazraki NP, Santamore WP, Sink JD. Effects of dynamic cardiomyoplasty on indices of left ventricular systolic and diastolic function in a canine model of chronic heart failure. J Thorac Cardiovasc Surg 1992;103:1207-13.

2. Anstadt GL, Schiff P, Baue AE. Prolonged circulatory support by direct mechanical ventricular assistance. Trans Am Soc Artif Organs 1966;12:72-9.

3. Brown CG, Schlaifer J, Jenkins J, et al. Effect of direct mechanical ventricular assistance on myocardial hemodynamics during ventricular fibrillation. Crit Care Med 1989;17:1175-80.

4. Chachques JC, Acar C, Portoghese M, et al. Dynamic cardiomyoplasty for long-term cardiac assist. Eur J Cardiothorac Surg 1992;6:642-7.

5. Hagege AA, Desnos M, Chachques JC, et al. Preliminary report: follow-up after dynamic cardiomyoplasty. Lancet 1990;335:1122-4.

6. Lowe JE, Anstadt MP, Van Trigt P, et al. First successful bridge to cardiac transplantation using direct mechanical ventricular actuation [see comments]. Ann Thorac Surg 1991;52:1237-43.

7. El Oakley RM, Jarvis JC. Cardiomyoplasty: a critical review of experimental and clinical results. Circulation 1994;90: 2085-90.

8. Aklog L, Murphy MP, Chen FY, et al. Right latissimus dorsi cardiomyoplasty improves left ventricular function by increasing peak systolic elastance $\left(\mathrm{E}_{\text {max }}\right)$. Circulation 1994;90: II112-9.

9. Schreuder JJ, van der Veen FH, van der Velde ET, et al. Beat-to-beat analysis of left ventricular pressure-volume relation and stroke volume by conductance catheter and aortic flow in cardiomyoplasty patients. Circulation 1995;91:2010-7.

10. Suga $H$, Sagawa $K$. Instantaneous pressure-volume relationships and their ratio in the excised, supported canine left ventricle. Circ Res 1974;35:117-26.

11. Suga $\mathbf{H}$, Hisano $\mathbf{R}$, Goto $\mathrm{Y}$, Yamada O, Igarashi $Y$. Effect of positive inotropic agents on the relation between oxygen consumption and systolic pressure volume area in canine left ventricle. Circ Res 1983;53:306-18.

12. Suga H. Ventricular energetics. Physiol Rev 1990;70:247-77.

13. Nakajima H, Niinami H, Hooper TL, et al. Cardiomyoplasty: probable mechanism of effectiveness using the pressurevolume relationship. Ann Thorac Surg 1994;57:407-15.

14. Bellotti G, Moraes A, Bocchi E, et al. Late effects of cardiomyoplasty on left ventricular mechanics and diastolic filling. Circulation 1983;88:304-8.

15. Ruggiero R, Thomas GA, Niinami H, et al. Double cardiomyoplasty: acute versus chronic results. Ann Thorac Surg 1993;56:31-7.

16. Kass DA, Baughman KL, Pak PH, et al. Reverse remodeling from cardiomyoplasty in human heart failure: external constraint versus active assist. Circulation 1995;91:2314-8.

17. Suga $H$, Hayashi $T$, Suehiro $S$, Hisano $R$, Shirahata $M$, Ninomiya I. Equal oxygen consumption rates of isovolumic and ejecting contractions with equal systolic pressure-volume areas in canine left ventricle. Circ Res 1981;49:1082-91.

18. Suga H, Hayashi T, Shirahata M, Suehiro S, Hisano R. Regression of cardiac oxygen consumption on ventricular pressure-volume area in dog. Am J Physiol 1981:240:H39-44.

19. Kawaguchi O, Goto Y, Futaki S, Ohgoshi Y, Yaku H, Suga $H$. The effects of dynamic cardiac compression on ventricular 
mechanics and energetics: role of ventricular size and contractility. J Thorac Cardiovasc Surg 1994;107:850-9.

20. Kawaguchi O, Goto Y, Futaki S, Ohgoshi Y, Yaku H, Suga $H$. Mechanical enhancement and myocardial oxygen saving by synchronized dynamic left ventricular compression. J Thorac Cardiovasc Surg 1992;103:573-81.

21. Suga H. Total mechanical energy of a ventricle model and cardiac oxygen consumption. Am J Physiol 1979;236:H498-505.

22. Jatene AD, Moreira LFP, Stolf NAG, Bocchi EA, Seferian P Jr, Fernandes PMP, et al. Left ventricular function changes after cardiomyoplasty in patients with dilated cardiomyopathy. J Thorac Cardiovase Surg 1991;102:132-8.

23. Cho PW, Levin HR, Curtis WE, et al. Pressure-volume analysis of changes in cardiac function in chronic cardiomyoplasty. Ann Thorac Surg 1993;56:38-45.
24. Magovern JA, Park SE, Cmolik BL, Trumble DR, Christlieb IY, Magovern GJ. Early effects of right latissimus dorsi cardiomyoplasty on left ventricular function. Circulation 1993;88:298-303.

25. Suga $H$, Sagawa K, Shoukas AA. Load independence of the instantaneous pressure-volume ratio of the canine left ventricle and effects of epinephrine and heart rate on the ratio. Circ Res 1973;32:314-22.

26. Sunagawa K, Maughan WL, Sagawa K. Effect of regional ischemia on the left ventricular end-systolic pressure-volume relationship of isolated canine hearts. Circ Res 1985;56:58695

27. Anderson WA, Anderson JS, Acker MA, et al. Skeletal muscle grafts applied to the heart: a word of caution. Circulation 1988;78:III180-90.

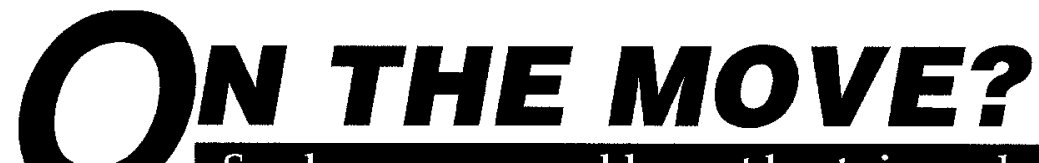

Send us your new address at least six weeks ahead

Don't miss a single issue of the journal! To ensure prompt service when you change your address, please photocopy and complete the form below.

Please send your change of address notification at least six weeks before your move to ensure continued service. We regret we cannot guarantee replacement of issues missed due to late notification.

\section{JOURNAL TITLE:}

Fill in the title of the journal here.

\section{OLD ADDRESS:}

Affix the address label from a recent issue of the journal here.

\section{NEW ADDRESS:}

Clearly print your new address here

Name

Address

City/State / ZIP
COPY AND MAIL THIS FORM TO:

Journal Subscription Services

Mosby-Year Book, Inc.

11830 Westline Industrial Dr.

St. Louis, MO 63146-3318
OR FAX TO:

314-432-1158

N/ Mosby
OR PHONE:

1-800-453-4351

Outside the U.S., call

314-453-4351 